J. Clin. Chem. Clin. Biochem.

Vol. 26, 1988, pp. $429-433$

(C) 1988 Walter de Gruyter \& Co.

Berlin - New York

\title{
A New Apa LI Restriction Fragment Length Polymorphism in the Low Density Lipoprotein Receptor $\left.\mathrm{Gene}^{1}\right),{ }^{2}$ )
}

By J. Geisel,

Abteilung für Klinische Chemie, Universität zu Köln,

B. Weisshaar,

Institut für Genetik, Universität zu Köln,

K. Oette,

Abteilung für Klinische Chemie, Universität zu Köln and

W. Doerfler,

Institut für Genetik, Universität zu Köln

(Received July 29, 1987//January 11/March 25, 1988)

Summary: The existence of a new Apa LI restriction fragment length polymorphism in the third intron of the low density lipoprotein (LDL) receptor gene was described. As a gene probe we used a newly constructed derivative of pLDLR 3 which did not contain the highly repetitive Alu-sequences in exon 18. This new gene probe detected all exon sequences containing restriction fragments, and enabled us to demonstrate all described polymorphisms, which might be useful for genetic linkage studies. Based on analysis of 72 unrelated normoand hypercholesterolaemic persons, the frequency of the allele A2, which showed the additional cutting site, was determined to be 0.05 . With the simplified gene probe, pLDLR $\Delta$, we also studied other polymorphisms. A clear linkage disequilibrium between the $P v u$ II and $M s p$ I polymorphisms was detected. This, and the previously described linkage disequilibrium of the two $M s p$ I polymorphisms, demonstrate that the LDL receptor gene is apparently less heterogeneous than expected from the number of described polymorphisms.

\section{Introduction}

The low density lipoprotein (LDL) receptor promotes the clearance of cholesterol-rich LDL particles from blood (1). Mutations in the LDL receptor gene cause familial hypercholesterolaemia, an autosomal dominant inherited disease (2). Individuals with one mutant gene for the LDL receptor (heterozygous familial hypercholesterolaemia) have about 2 fold elevated levels of LDL in plasma and an increased risk for myocardial infarction. In individuals who carry two mutant genes (homozygous familial hypercholesterolaemia), the LDL levels are even 3-6 fold higher than normal, and coronary heart disease frequently occurs in childhood. The prevalence of heterozygous familial hypercholesterolaemia appears to be approximately 1 in 500 in most countries of the world. The homozygous form is about 1 in 1 million (3).

\footnotetext{
1) Funding organisations: Moritz'sche Stiftung, Deutsche Forschungsgemeinschaft (SFB 74)

2) Enzymes:

Restriction endonuclease (EC 3.1.21...)

Apa LI from Acetobacter pasteurianus

Bam HI from Bacillus amyloliquefaciens

Bsp M 2 from Bacillus species M

Dra III from Deinococcus radiophilus

Eco RI from Escherichia coli

Kpn I from Klebsiella pneumoniae

Msp I from Moraxella species

Pst I from Providencia stuartii

Pvu II from Proteus vulgaris

T 4 DNA ligase, EC 6.5.1.1
} 
Recently, the full-length cDNA of the LDL receptor gene has been cloned (4), and a variety of mutations in this gene have been found among patients with familial hypercholesterolaemia $(2,5-9)$. These experiments were usually carried out by hybridizing genomic DNA or cytoplasmic m-RNA with the cDNA to survey both genomic gene organisation and m-RNA expression. Since highly repetitive Alu sequences were present at the $3^{\prime}$ end of the cDNA, direct hybridization experiments using the full-length cDNA clone were impossible. Therefore fragments of the cDNA, which detect only some of the 18 exons, were employed for hybridization $(9,10)$. The most frequently used gene probe was the Bam $\mathrm{HI}$ fragment which contained complementary sequences of exon 10 to 18 . For this reason, most of the detected polymorphisms have been localized in the $3^{\prime}$ region of the gene. In the present work, we prepared a cDNA probe from pLDLR 3 which can detect all exon-containing restriction fragments of the $\mathrm{LDL}$ receptor gene without further probe processing.

To date, 11 restriction fragment length polymorphisms have been described in the LDL receptor gene $(10-18)$. For the diagnosis of familial hypercholesterolaemia, the polymorphisms are used to detect alleles which correlated with the disease in pedigree analysis (19). The identification of the new Apa LI polymorphism, which was localized in the $5^{\prime}$ region of the gene, provided additional information for genetic analysis.

\section{Materials and Methods}

Preparation of the gene probe pLDLR $\Delta$

The full-length cDNA clone pLDLR 3 was obtained from the American Type Culture Collection (Rockville, Md., USA, ATCC-Nr. 57005). Cloned pLDLR 3 was cleaved with Bsp M2 (Biolabs, Beverly, MA, USA), which cuts at nucleotide position 4580 of the cDNA. The linear molecule was then partially digested with Dra III (Biolabs), which cleaves at positions 3115 and 3626 . The resulting fragments were separated by preparative agarose gel electrophoresis (6 g/l, Type IIa, Sigma, Deisenhofen, FRG), and the $\sim 7 \times 10^{3}$ base pairs fragment was eluted. After Klenow' fragment treatment (Boehringer Mannheim, FRG) to prepare blunt ends, the fragment was recircularized with T4 DNA ligase (BRL, Eggenstein, FRG). E. coli cells, strain HB 101, were made competent by the method of Hanahan and transformed with the ligation products (20). One clone, which showed the expected cleavage patterns with Dra III, Hae III, Rsa I or Msp I was selected and was designated pLDLR $\Delta$. Plasmid DNA was prepared by the Triton X-100 lysis method and purified by $\mathrm{CsCl}$ gradient centrifugation (21).

\section{Other gene probes}

Gene probes to detect only certain exons were prepared by digestion of $5 \mu \mathrm{g}$ pLDLR $\triangle$ DNA with $P v u$ II (Boehringer Mannheim, FRG). The resulting fragments were separated by preparative agarose gel electrophoresis $(20 \mathrm{~g} / \mathrm{l})$. The elution of the 268 bp $P v u$ II fragment was carried out with the Biotrap of Schleicher and Schüll (Dassel, FRG).

\section{Labelling of the gene probes}

$100 \mathrm{ng}$ of pLDLR $\Delta$ was radioactively labeled with $\left[{ }^{32} \mathrm{P}\right] \mathrm{dCTP}$ by the nick translation kit of Boehringer Mannheim (FRG). Purified DNA fragments were radiolabeled by an oligonucleotide priming kit (Amersham, Braunschweig, FRG). The unincorporated nucleotides were separated on a Sephadex G-50 column (Pharmacia, Freiburg, FRG). The specific activity of the probes was greater than $5 \times 10^{8}$ counts/min $\times \mu g$.

\section{DNA isolation}

Blood samples were collected in EDTA Monovettes (Sarstedt, Nümbrecht, FRG) and frozen at $-70^{\circ} \mathrm{C}$. DNA was prepared from leukocytes by the Triton X-100 lysis method (22).

\section{DNA digestion and Southern blot}

Ten $\mu \mathrm{g}$ of human DNA was cleaved with restriction enzymes Pvu II, Msp I, Pst I, Bam HI (Boehringer Mannheim, FRG) or Apa LI (Biolabs, Beverly, MA, USA), as recommended by the manufacturer, and the fragments were separated on agarose gels (Pvu II, Pst I, Apa LI/Bam HI fragments in agarose, $8 \mathrm{~g} / \mathrm{l}$; $M s p$ I fragments in agarose, $20 \mathrm{~g} / \mathrm{l})$. The fragments were transferred to nitrocellulose filters (Ba 85 , Schleicher \& Schüll, Dassel, FRG) and fixed by baking at $80^{\circ} \mathrm{C}(21)$.

\section{Hybridization}

The conditions for hybridization have been previously described (23). The posthybridization washes consisted of three $10 \mathrm{~min}$ washes at room temperature in a solution of $2 \times \operatorname{SSC}(1 \times \operatorname{SSC}$ $=\mathrm{NaCl}, 0.15 \mathrm{~mol} / \mathrm{l}$, sodium citrate, $15 \mathrm{mmol} / \mathrm{l})$ and $\mathrm{SDS}, 1 \mathrm{~g} / \mathrm{l}$, and three $15 \mathrm{~min}$ washes at $56^{\circ} \mathrm{C}$ in a solution of $0,1 \times \mathrm{SSC}$ and SDS, $1 \mathrm{~g} / \mathrm{l}$. The nitrocellulose filters were then exposed to $\mathrm{X}$-ray films (XAR, Kodak, USA) for $1-4$ days at $-70^{\circ} \mathrm{C}$.

\section{Collective}

Patients with familial hypercholesterolaemia (48 individuals), type IIa, were followed up in the outpatient clinic of our department. These patients had a family history of hypercholesterolaemia and in some cases of myocardial infarctions and tendon xanthomata. The LDL-cholesterol ranged between 180 and $240 \mathrm{mg} / \mathrm{dl} \cong 4.7$ and $6.2 \mathrm{mmol} / 1$ during a cholesterollowering diet and treatment with one or more lipid-lowering drugs. Normolipidaemic subjects (24 individuals) were laboratory personnel and medical students.

\section{Results}

\section{Improved LDL receptor gene probe}

As expected for hybridization probes which carried Alu repeats, hybridization experiments were impossible with pLDLR 3. Using two restriction sites in close proximity to the Alu repeats (nucleotide position 3717 and 4478 , fig. 1) these sequences were deleted in pLDLR 3. The resulting clone was named pLDLR $\Delta$ (for details see Materials and Methods). In the analytical restriction experiments, we took into account the modification in the promotor region of pLDLR 3 as mentioned by the American Type Culture Collection. With pLDLR $\Delta$ all exon sequences containing restriction fragments could be detected. An example of a genomic Southern blot is shown in figure 2. 


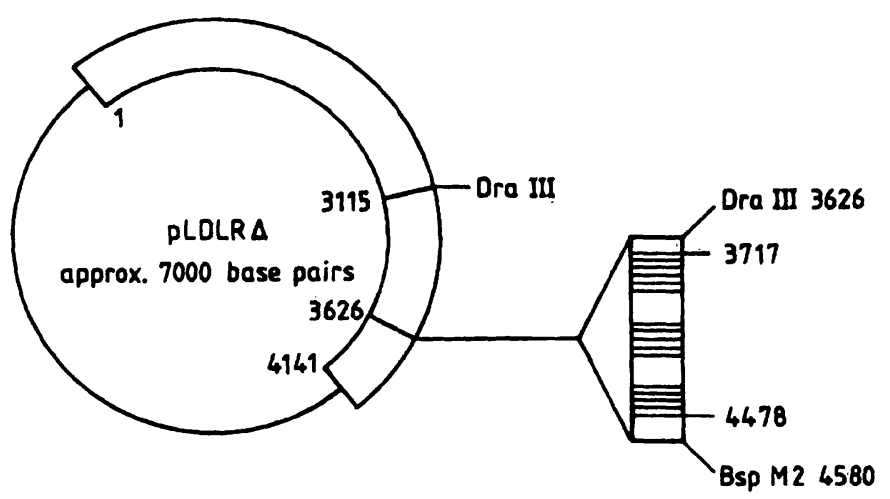

Fig. 1. Structure of pLDLR $\Delta$

The Alu sequences containing part of pLDLR 3 between the second Dra III site (cDNA nucleotide position 3626, numbers as in 1.c. (4)) and the Bsp M2 site (cDNA nucleotide position 4580) was deleted. The resulting clone was named pLDLR $\Delta$.

vector part, $=\mathrm{cDNA}, \simeq$ deleted part
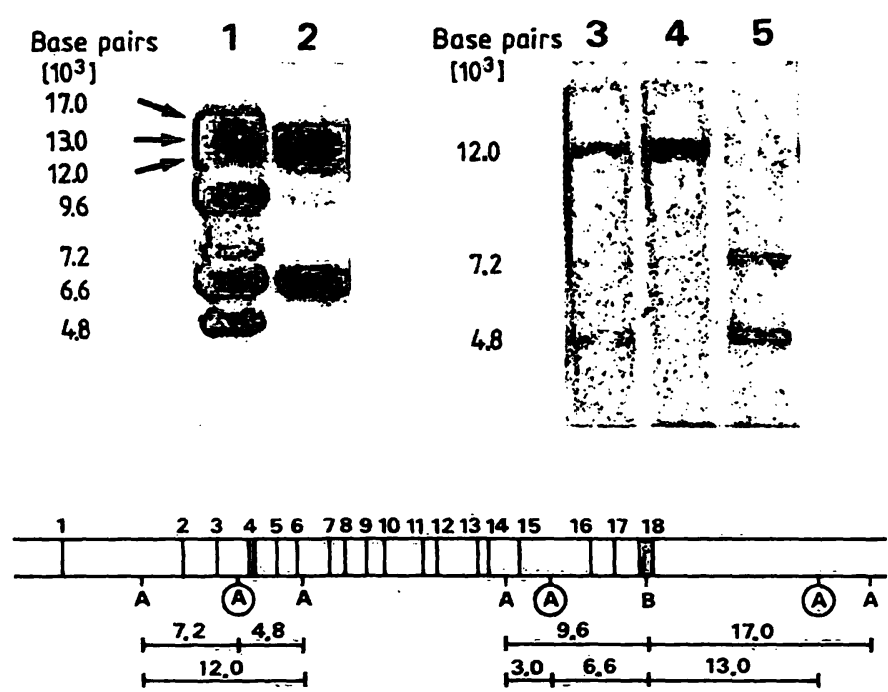

Fig. 2. Apa LI polymorphisms in the LDL receptor gene. In the upper part, the Southern blot analyses of DNA cleaved with Apa LI and Bam HI are demonstrated. In the left panel, pLDLR $\Delta$ was used for hybridization to detect all three polymorphisms. In the right panel the new Apa LI polymorphism in intron 3 is shown solely by hybridization with the exon 3- and 4-specific Pvu II fragments. In the lower part a rough restriction map of the LDL receptor gene is shown. The relevant Apa LI sites (A), Bam HI sites (B) and additional cutting sites $(O)$ and the resulting fragments as well, as their length $\left(10^{3}\right.$ base pairs) are indicated.

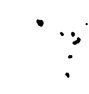

\section{New Apa LI polymorphism}

DNA from normolipidaemic individuals or from patients with familial hypercholesterolaemia was assayed for the two Apa LI polymorphisms previously described (15). Double cleavage with Apa LI and Bam HI improved the differentiation of fragments (15). The gene probes used contained sequences from exons 16 to 18 . After hybridization with the pLDLR $\Delta$ gene probe, which detects $3^{\prime}$ and also $5^{\prime}$ sequences, a third polymorphic Apa LI site became obvious (fig. 2). Two additional fragments with sizes of about 4.8 and 7.2 $\times 10^{3}$ base pairs were detectable in some subjects. We designated the allele with the additional cutting site $\mathrm{A} 2$, and the allele without this site A1. By double cleavage with $A p a$ LI and Kpn I, Eco RI or Bam HI the additional $A p a \mathrm{LI}$ site in allele A2 was located in intron 3. With the 268 base pairs $P v u$ II fragment from pLDLR $\Delta$, which detects exons 3 and 4 , this polymorphism could be selectively visualized (right panel fig. 2).

The allele frequencies of the new Apa LI polymorphism were determined in our collective of 72 unrelated individuals. For all investigated persons the frequencies of allele A1 and allele A2 are 0.95 and 0.05 , respectively. The normolipidaemic population (24 individuals) showed in 23 cases the genotype A1A1, and in one case the genotype $\mathrm{A} 1 \mathrm{~A} 2$. In the population of independent patients with familial hypercholesterolaemia (48 individuals), the genotype $\mathrm{A} 1 \mathrm{~A} 1$ was present in 43 cases, A1A2 in 4 cases, and A2A2 in one case.

Mendelian inheritance of the newly discovered polymorphism was demonstrated in three families. One example is shown in figure 3 . In this family the allele A2 was found to be associated with familial hypercholesterolaemia.



Fig. 3. Pedigree of a family with the Apa LI polymorphism within intron 3 of the LDL receptor gene. O $\mathrm{normal}$, female and male

O 1 heterozygous familial hypercholesterolaemia - homozygous familial hypercholesterolaemia A diagonal stroke indicates that the family member died before onset of the study. The genotype for the polymorphic Apa LI site in intron 3 is also indicated. A1: Apa LI site absent, A2: Apa LI site present in intron 3. 
Linkage disequilibrium between polymorphisms

Including the new Apa LI polymorphism, 12 restriction fragment length polymorphisms were described in the LDL receptor gene. Three polymorphisms were detected for $A p a \mathrm{LI}$, and two for Msp I. In our studies we considered the Msp I polymorphism which is located in exon 18 and the $A p a$ LI polymorphism in intron 15. The allele frequencies of these and of the $P v u$ II and Pst I polymorphisms were determined in our collective. Following a proposal of the Committee on Human Gene Mapping by Recombinant DNA Techniques, the alleles have been designated A1 and A2 according to decreased allelic frequencies (24). A comparison of the homozygous $P v u$ II genotypes $\mathrm{A} 1 \mathrm{~A} 1$ and A2A2 with the corresponding Msp I genotypes of the same patients revealed a striking linkage disequilibrium between the $P v u$ II and the $M s p$ I polymorphisms.(tab. 1). In 57 out of 61 cases, the $P v u$ II genotypes $\mathrm{A} 1 \mathrm{~A} 1$ and $\mathrm{A} 2 \mathrm{~A} 2$ were associated to the corresponding $M s p \mathrm{I}$ alleles $\left(\chi^{2}=14.92, \mathrm{f}=1\right.$, $\mathrm{p}<0.001)$. A similar relationship between the genotypes of other restriction enzymes studied was not found.

\section{Discussion}

In order to obtain a gene probe which facilitated detection of all exons in the LDL receptor gene, we deleted the Alu sequences in pLDLR 3. These sequences were located in exon 18 and were involved in some rearrangements detected in patients with familial hypercholesterolaemia $(5,25)$. Alu repeats occur about 300000 times in the human genome (26).
All of these repeats hybridized in genomic Southern blot experiments when the pLDLR 3 probe was used. With the newly constructed plasmid pLDLR $\Delta$, a gene probe was available to study all exon-containing restriction fragments of the LDL receptor gene in one experiment. All restriction fragment length polymorphisms described so far were detectable with this gene probe, which has thus proved of great practical importance for genetic linkage studies in families with inherited hypercholesterolaemia. A third Apa LI polymorphism in the LDL receptor gene has emerged by screening with the gene probe pLDLR $\Delta$. The results of mapping experiments using an exon 3-and 4-specific fragment for hybridization showed the polymorphic site to reside in intron 3 . The new polymorphic Apa LI site is located closer to the $\dot{S}^{\prime}$ end than any of the other described polymorphisms (fig. 2). The frequency of the rare allele $A 2$ is 0.05 in all studied persons. In the population of patients with familial hypercholesterolaemia the A2 allele occurred at a higher frequency than in normolipidaemic persons. Whether or not a linkage disequilibrium of allele $\mathrm{A} 1$ and allele $\mathrm{A} 2$ exists between the two populations can only be clarified by the investigation of a larger number of persons. Pedigree analysis to determine whether an association exists between the A2 allele and familial hypercholesterolaemia, as in the analysis shown in figure 3 , is in progress.

The three Apa LI polymorphisms together with the 9 other described polymorphisms permit the identification of a large number of different alleles. However, the actual number of different alleles observed is smaller than the theoretically possible number. The LDL receptor gene seems to be less heterogeneous than expected from the number of polymorphisms.

Tab. 1. Correlation of the polymorphism-defined genotypes of the LDL receptor gene.

For Msp I the polymorphism in exon 18, for Apa LI the polymorphism in intron 15 are considered in the analysis. The $19,9.6,3.4,0.44 \times 10^{3}$ base pairs fragment designated the A1 allele of Pvu II, Apa LI, Pst I and Msp I. The A2 allele is characterized for Pvu II, Apa LI, Pst I and $M s p$ I by the 16, 6.6, 2.8 and $0.47 \times 10^{3}$ base pairs fragment, respectively.

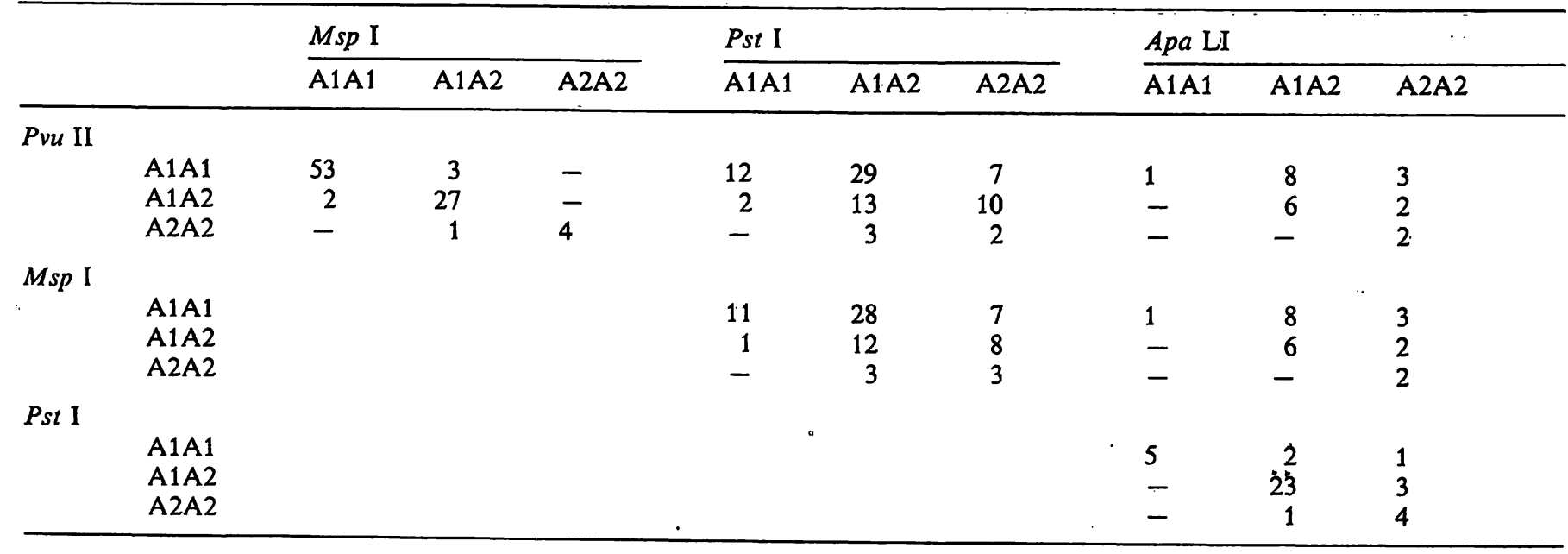


Here we report the linkage disequilibrium between the $P v u$ II and Msp I genotypes. The linkage disequilibrium of the two Msp I polymorphisms was published previously; as a result two haplotypes can now be characterized. In haplotype 1 , the $P v u$ II site is absent at the polymorphic position, and the two additional Msp I sites are present. In haplotype 2, the additional $P v u$ II site is present, and the two $M s p$ I sites are absent.

Since the number of heterozygous individuals for the Pst I and Apa LI polymorphisms was very large, correlations with other polymorphisms were not possible (tab. 1). In such cases haplotypes can only be established by family analysis. In phenylketonuria, it was shown that polymorphism-defined haplotypes were associated with the disease (27). In South Africa, such an association was described for familial hypercholesterolaemia (28). This finding and a frequently detected mutation in specific ethnic groups, causing familial hypercholesterolaemia, can presumably be interpreted as a founder gene effect $(29,30)$. Whether it will be possible to detect distinct haplotypes, which frequently appear in patients with familial hypercholesterolaemia, in a central European population, remains to be elucidated in the future by pedigree analysis.

\section{Acknowledgement}

We wish to thank $R$. Malchow for excellent technical assistance. This research was supported by the Moritz'sche Stiftung and by a grant from the Deutsche Forschungsgemeinschaft (SFB 74-C1).

\section{References}

1. Goldstein, J. L., Brown, M. S., Anderson, R. G. W., Russell, D. W. \& Schneider, W. J. (1985) Annu. Rev. Cell Biol. I, 1-39.

2. Brown, M. S. \& Goldstein, J. L. (1986) Science 232, 34-47.

3. Goldstein, J. L. \& Brown, M. S. (1983) In: The Metabolic Basis of Inherited Disease (Stanbury, J. B., ed.) pp. 672712, McGraw-Hill, New York.

4. Yamamoto, T., Davis, C. G., Brown, M. S., Schneider, W. J., Casey, M. L., Goldstein, J. L. \& Russell, D. W. (1984) Cell 39, 27-38.

5. Lehrmann, M. A., Schneider, W. J., Südhof, T. C., Brown, M. S., Goldstein, J. L. \& Russell, D. W. (1985) Science 227, 140-146.

6. Lehrmann, M. A., Goldstein, J. L., Brown, M. S., Russell, D. W. \& Schneider, W. J. (1985) Cell 41, 735-743.

7. Hobbs, H. H., Brown, M. S., Goldstein, J. L. \& Russell, D. W. (1986) J. Biol. Chem. 261, 13114-13120.

8. Lehrmann, M. A., Goldstein, J. L., Russell, D. W. \& Brown, M. S. (1987) Cell 48, 827-835.

9. Horsthemke, B., Dunning, A. \& Humphries, S. (1987) J. Med. Genet. 24, 144-147.

10. Humphries, S., Horsthemke, B., Seed, M., Holm, M., Wynn, V., Kessling, A. M., Donald, J. A., Jowett, N., Galton, D. J. \& Williamson, R. (1985) Lancet I, 10031005.

11. Funke, H., Klug, J., Frossard, P., Coleman, R. \& Assmann, G. (1986) Nucl. Acids Res. 14, 7820.

12. Kotze, M. J., Retief, A. E., Brink, P. A. \& Weich, H. F. H. (1986) S. Afr. Med. J. 70, 77-79.

13. Kotze, M. J., Langenhoven, E., Dietzsch, E. \& Retief, A. E. (1987). Nucl. Acids Res. 15, 376.

14. Hobbs, H. H., Esser, V. \& Russell, D. W. (1987) Nucl. Acids Res. 15, 379.

15. Leitersdorf, E. \& Hobbs, H. H. (1987) Nucl. Acids Res. $15,2782$.
16. Geisel, J., Weisshaar, B., Oette, K., Mechtel, M. \& Doerfler, W. (1987) Nucl. Acids Res. 15, 3943.

17. Steyn, L. T., Pretorius, A., Brink, P. A. \& Bester, A. J. (1987) Nucl. Acids Res. 15, 4702.

18. Yamakawa, K., Okafuji, T., Iwamura, Y., Russell, D. W. \& Hamaguchi, H. (1987) Nucl. Acids Res. 15, 7659.

19. White, R., Leppert, M., Bishop, D. T., Barker, D., Berkowitz, J., Brown, C., Callahan, P., Holm, T. \& Jerominki, L. (1985) Nature 313, 101-105.

20. Hanahan, D. (1983) J. Mol. Biol. 166, 557-580.

21. Maniatis, T., Fritsch, E. F. \& Sambrook, J. (1982) Molecular Cloning: A Laboratory Manual, Cold Spring Harbor, New York.

22. Kunkel, L. M., Smith, K. D., Boyer, S. H., Borgaonkar, O. S., Wachtel, S. S., Miller, O. J., Breg, W. R., Jones, H. W. \& Rary, J. M. (1977) Proc. Natl. Acad. Sci. USA 74, 1245-1249.

23. Stabel, S., Doerfler, W. \& Friis, R. R. (1980) J. Virol. 36, $22-40$.

24. Skolnick, M. H., Willard, H. F. \& Menlove, L. A. (1984) Cell Genet. 37, 210-248.

25. Lehrmann, M. A., Russell, D. W., Goldstein, J. L. \& Brown, M. S. (1987) J. Biol. Chem. 262, 3354-3361.

26. Hobbs, H. H., Lehrmann, M. A., Yamamoto, T. \& Russell, D. W. (1985) Proc. Natl. Acad. Sci. USA 82, 7651-7655.

27. DiLella, A. G., Marvit, J., Brayton, K. \& Woo, S. L. C. (1987) Nature 327, 333-336.

28. Brink, P. A., Steyn, L. T., Coetzee, G. A. \& Van der Westhuyen, D. R. (1987) Hum. Genet. 77, 32-55.

29. Hobbs, H. H., Brown, M. S., Russell, D. W., Davignon, J. \& Goldstein, J. L. (1987) N. Engl. J. Med. 317, 734-737.

30. Lehrmann, M. A., Schneider, W. J., Brown, M. S., Davis, C. G., Elhammer, A., Russell, D. W. \& Goldstein, J. L. (1987) J. Biol. Chem. 262, $401-410$.

Dr. J. Geisel

Abteilung für Klinische Chemie

Universität zu Köln

Joseph-Stelzmannstraße 9

D-5000 Köln 41 


\section{.}

